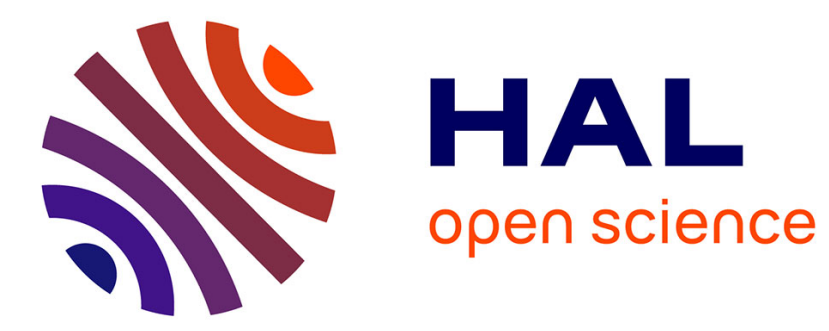

\title{
Democratising design in scientific innovation: application of an open value network to open source hardware design
}

Maria Frangos, Joshua Pearce, Tiberius Brastaviceanu, Ahmed Aki

Mahmoud, Abran Khalid

\section{To cite this version:}

Maria Frangos, Joshua Pearce, Tiberius Brastaviceanu, Ahmed Aki Mahmoud, Abran Khalid. Democratising design in scientific innovation: application of an open value network to open source hardware design. Cumulus Hong Kong, 2016. hal-02113462

\section{HAL Id: hal-02113462 https://hal.science/hal-02113462}

Submitted on 28 Apr 2019

HAL is a multi-disciplinary open access archive for the deposit and dissemination of scientific research documents, whether they are published or not. The documents may come from teaching and research institutions in France or abroad, or from public or private research centers.
L'archive ouverte pluridisciplinaire HAL, est destinée au dépôt et à la diffusion de documents scientifiques de niveau recherche, publiés ou non, émanant des établissements d'enseignement et de recherche français ou étrangers, des laboratoires publics ou privés. 


\title{
Democratising design in scientific innovation: application of an open value network to open source hardware dlesign
}

\section{Maria Frangos}

Carleton University, Montreal, Canada

mariafrangos@gmail.com

\section{Joshua Pearce}

Michigan Technological University, Houghton, United States

pearce@mtu.edu

\section{Tiberius Brastaviceanu}

Sensorica, Montreal, Canada

tiberius.brastaviceanu@gmail.com

\section{Ahmed Akl Mahmoud}

Arab Academy for Science, Technology and Maritime Transport, Egypt akl@aast.edu

\author{
Abran Khalid \\ Sensorica, Pakistan \\ Abrankhalid@gmail.com
}

\section{ABSTRACT}

Open source hardware (OSH) development has been gaining momentum in recent years with several communities attempting to formalise its various aspects. One particularly promising area is the design of open source scientific hardware. Previous work has shown that the use of digital fabrication techniques has allowed scientists to make high-quality scientific tools for $1-10 \%$ of the cost of commercial proprietary equipment. Open source scientific hardware (and the open science movement in which it is situated) is part of a larger social shift characterised by open production methodologies, and decentralised and distributed models of collaboration. Design is also increasingly involved in supporting open production, both in terms of designing and developing technical infrastructures, and in terms of encouraging and sustaining processes that promote collaboration and openness.

This paper builds on the work of open source scientific hardware and emerging concepts in participatory design with a focus on commons-based peer production. How do open production environments foster engagement and innovation? Can distributed modes of production support the design of open source scientific hardware? To answer these questions, a design research case study was undertaken to investigate the design and social impact of a collaboratively designed open source hardware instrument developed by Sensorica, an open value network, in collaboration with an academic laboratory. The project's goal was to engage with makers and communities around the world in order to encourage its wider adoption, future evolution and continued development.

\section{Keywords}

open source hardware, commons-based peer production, participatory design

\section{INTRODUCTION}

The democratisation of digital technologies and proliferation of open source software (Corsín Jiménez, 2014; Marttila \& Botero, 2013) has provided individuals and groups with unparalleled access to design and production tools. Following the success of free and open source software (FOSS), the production of open source hardware (OSH) has been gaining momentum (OSHWA, 2016b; Seravalli, 2012, 2013) in recent years with several communities attempting to formalise its various aspects. These include Peerto-Peer (P2P) communities supporting OSH production environments through distributed communication networks (Bauwens, 2009; Benkler, 2006); communities investigating licensing issues, such as the Open Hardware License (OHL); and Engineering and Design communities creating participatory platforms that promote access to, and sharing of, hardware designs and code (Corsín Jiménez, 2014).

One particularly promising area is the design of open source scientific hardware (Pearce, 2012; 2014). Open source scientific hardware, and the 'open science' (Dasgupta \& David, 1994) movement in which it is situated, is part of a larger social shift characterised by open production methodologies and new, decentralised models of collaboration - or commons-based peer production (Benkler, 2006; Bauwens, 2009). From data acquisition and analysis, to the open production of tangible instruments, open science has grown into a coherent set of interconnected processes, defining a new approach to scientific inquiry and technological development (Brastaviceanu, 2016). In addition to lowering costs, scientific innovation benefits from more networked, open, and collaborative environments (Baldwin \& Hippel, 2011; Chesbrough, 2003).

Design is also increasingly involved in supporting open production, both in terms of designing and developing technical infrastructures, and in terms of facilitating and nourishing processes that promote collaboration and openness in diverse fields 
(Seravalli, 2013). From the 'open design' movement (e.g. Halpern et al., 2013; Marttila \& Botero, 2013; Phillips \& Baurley, 2007; Phillips et al., 2014; van Abel et al., 2011) to collaborative practices in community contexts (e.g. Björgvinsson et al., 2010; Björgvinsson et al., 2012; Hillgren et al, 2011; Karasti \& Syrjänen, 2004; Le Dantec \& DiSalvo, 2013), an increasing number of participatory design scholars are shifting focus from a product design view toward socialised and long-term processes in open and public environments.

This paper builds on the work of open source scientific hardware (OSSH) and emerging concepts in participatory design (e.g. Björgvinsson, 2014; Marttila et al., 2014; Marttila \& Botero, 2013; Seravalli, 2012, 2013) with a focus on commons-based peer production. How do open production environments foster engagement and innovation? Can open products be designed, produced and distributed in a sustainable way? How can decentralised modes of production support the design of OSSH? To answer these questions, the development of a collaboratively designed OSH project by Sensorica, an open value network (OVN) based on principles of commons-based peer production (Bauwens, 2009), and an academic laboratory will be presented. The challenges of this approach and lessons learned will also be discussed.

\section{Literature review}

An increasing number of scholars are commenting on the production of open source hardware and tangible products - from social science perspectives (e.g. Corsín Jiménez, 2014), to processes (e.g. Raasch, 2011; Raasch et al., 2009) and principles (e.g. Coleman et al., 2014) of open design, to the production and practical application of open source devices (e.g. Gibb, 2014). Others have approached the production of open source hardware philosophically, from a commons-based peer-to-peer perspective (e.g. Bollier, 2009; Benkler, 2006; Benkler \& Nissenbaum, 2006; Hess \& Ostrom, 2006, 2007; Siefkes, 2012).

Located at the interstices of open source hardware, open science and the knowledge commons, an emerging research area is the production of open source scientific instruments. Proponents of open source scientific hardware have cited an increase in return on investment $(\mathrm{ROI})$ and access to low-cost devices as long-term benefits of applying open production processes to the design and development of these instruments. For example, previous work has shown that the use of digital fabrication techniques (e.g. 3-D printing and laser cutting) have allowed scientists to make (and replicate) high-quality scientific tools for $1-10 \%$ of the cost of commercial proprietary equipment (e.g. Pearce, 2012, 2014; Zhang et al., 2013; Baden, et al., 2014; Schausberger, et al., 2015; Mista et al., 2016). This approach has the potential to create tremendous value for the scientific community (Pearce, 2015a), as it allows replication for approximately the cost of materials (Pearce, 2015b).

Although the number of peer-reviewed studies on the production of open source scientific hardware has increased over recent years, much of the research focuses on economic value and improved innovation due to customisation for specific experiments. However, an increasing number of scholars are also exploring the collaborative practices and environments in which open source scientific innovation takes place (e.g. Langlois \& Garzarelli,
2008; Petzel et al., 2010; Ziaie, 2014). For example, Petzel et al. (2010) consider how the commons can support innovation in the production of scientific hardware, while Baldwin and Hippel (2011) expound on the turn from producer innovation to user innovation in open, collaborative environments.

A number of design researchers (e.g. Baek \& Manzini, 2012; Björgvinsson, 2014; Le Dantec \& Disalvo, 2013; Marttila \& Botero, 2013; Marttila, 2014; Seravalli, 2012; 2013) are also focusing on the shift from producer to user innovation. In addition to interrogating aspects of authorship, ownership, access and distribution rights, these scholars place emphasis on the social processes of design, embracing more extensive interpretations of how design activities are carried out. This area of research focuses on 'infrastructuring' - an emerging concept in participatory design that represents a move from project-based design in professional settings toward open-ended, long-term processes in community contexts (Björgvinsson et al., 2010). This paper offers an interdisciplinary perspective on open source scientific hardware by applying the concept of infrastructuring to the production of an open source scientific instrument designed and developed within an open value network. Furthermore, it considers whether certain concepts of infrastructuring, such as open-ended and long-term processes, can be applied to the design of 'useful products' (Le Dantec \& Disalvo, 2013) with fixed timelines.

\section{Methodology}

This study employs a design research case study approach to analyse the design and production of an open source solar scientific instrument - a photovoltaic (PV) characterisation apparatus -, within an open value network. This approach supports the methodological traditions of participatory design, by directly implicating researchers in the design project, and thus makes the results of the research more relevant to design practitioners (IIpo et al., 2011).

The data sources in this study consist of a document review of the design and research process, correspondence between collaborators, source files of process documents and group discussions between the project's major contributors (email correspondence and a live, recorded group discussion) - some of whom are co-authors of this paper.

\section{Design process}

\section{Project description}

The project's goal, as outlined in a report by Meyer et al. (2015), was to engage with makers and communities around the world in order to maximise the social impact of the solar PV characterisation apparatus device (see Figure 1) as an open source scientific instrument, and to encourage its wider adoption, continuity, future evolution and continued development. The characteristics of the scientific instrument were designed and developed in accordance with open science values and principles:

- Open source - integration of open innovation standards, documenting and sharing all layers of design;

- Shareable - portable, user friendly, and rugged, with the 
potential to track activity and use history as a shared community asset;

- Modular - allowing individual components to be easily repaired, replaced, exchanged or upgraded; a perpetual product;

- Interoperable - utilisation of common design standards to ensure compatibility with other devices or systems;

- Social - engagement and collaboration between communities of designers and communities of use to best design for on the ground needs;

- Ethical, ecological and sustainable (Meyer et al., 2015).

The design and development of the device was planned over four phases: Design Characteristics, Design, Prototype, and Product; and involved digital fabrication techniques (3-D printing) for the device itself, as well as user interface design and front-end software development for controlling the device.

All documented aspects of the project (e.g. project documents, reports, bill of materials and process videos - see Figure 2) were made publically available. In addition, versions of the software code were stored on Github, a software repository. The device design and code were distributed through an Attribution-ShareAlike (CC:BY:SA) license, which allows anyone to remix, tweak, and build upon the work (even for commercial purposes), as long as credit is given to the original producers and new creations are licensed under identical terms (Creative Commons, 2016.).

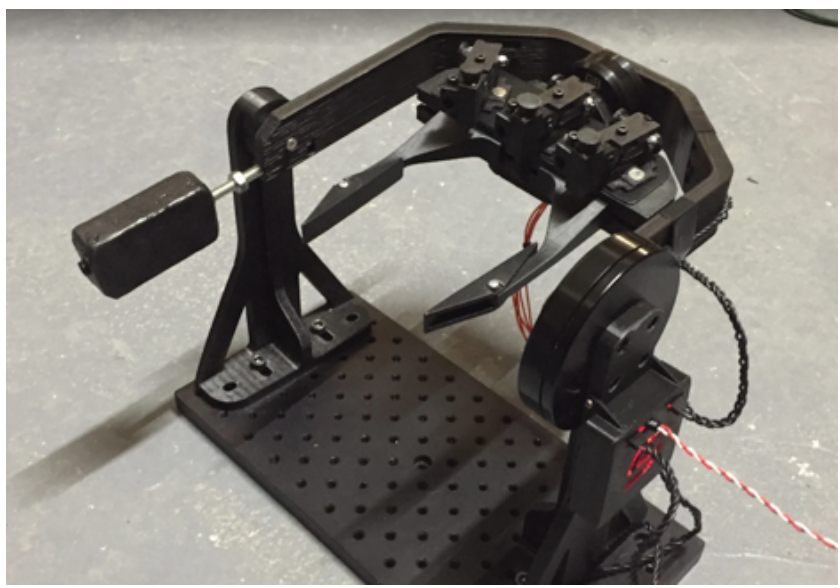

Figure 1. PV characterisation. Two-axis gimbal mounting system. Image source: Sensorica

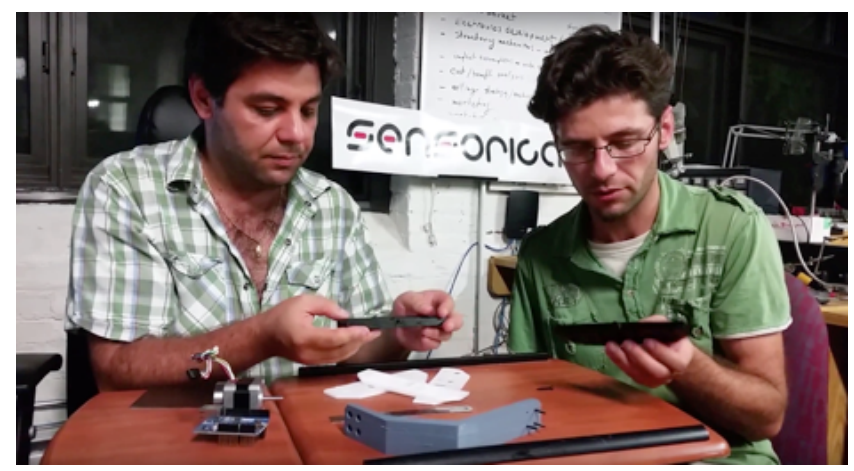

Figure 2. Screen capture of video of demonstration of two-axis PV characterisation mounting system. Source: Sensorica

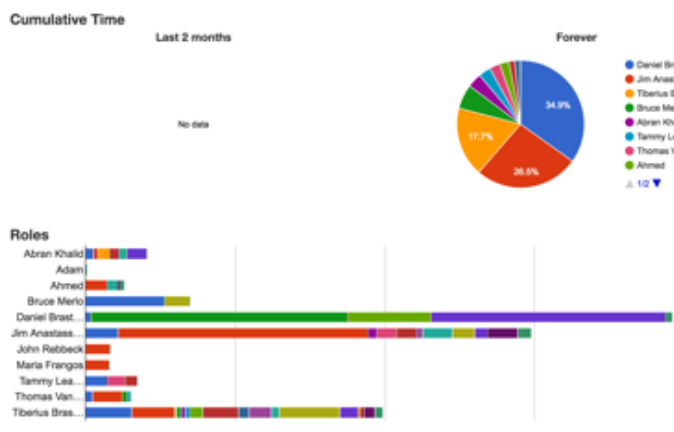

Figure 3. Top right: Visualisation of contributions. Bottom: Horizontal bar graph of contributions per user and segmented by tasks (colour codes correspond to task types). Image source: Sensorica

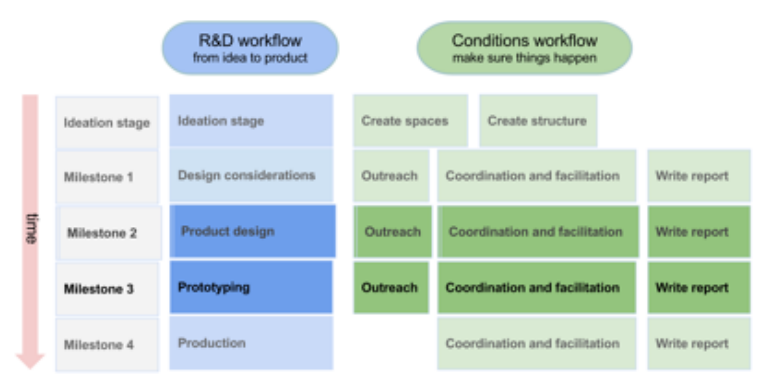

Figure 4. Workflow chart. Image source: Sensorica

\section{Participation and collaboration in an open value network}

A total of eleven people from five countries participated in the apparatus' design and development, logging over 200 time contributions (see Figure 3) in Sensorica's Network Resource Planning and Value Accounting System (NRP-VAS) - a web-based resource planner that distributes funds equitably amongst contributors, in proportion to their contributions. In addition, Sensorica created specific project roles for project lead, outreach, orientation, coordination and facilitation. Tools for collaboration included a hackpad (a collaborative platform), Google groups and Google Hangouts.

In addition to maximising the social impact of the device, the design of the solar PV characterisation apparatus also served as a pilot project in which to test the dynamic between an open value network and a classical institution (in this case, a university), using open production methodologies and Sensorica's approach to governance. Based on principles of co-production, self-organisation, and stewardship of the commons, the premise behind OVN is that it allows individuals and organisations to co-create and aggregate value through lateral and large-scale coordination, cooperation and collaboration. For the PV project, Sensorica created project governance, workflow (see Figure 4) and value equation agreement documents, and made them publically available.

\section{Project Results}

According to the academic partner, initial outreach was successful and a diverse group of Sensorica members, representing design, 
communication, software development, and hardware development, participated in the ideation phase. As an open source project, the initial design concepts (see Figure 5 for one example) were well documented and provide a good starting point for anyone (including those outside of the Sensorica network) wishing to explore the concepts further. To this end, Sensorica's approach to ideation could benefit other projects seeking to develop a similar system. However, while Sensorica's open value network is designed to sustain open, collaborative and decentralised modes of production, this approach posed some challenges with respect to producing and delivering the apparatus. For example, while there was an explosion of creative design solutions (due to the diverse backgrounds of participating affiliates), this also created a significant amount of additional work to cull the core design down to a single concept.

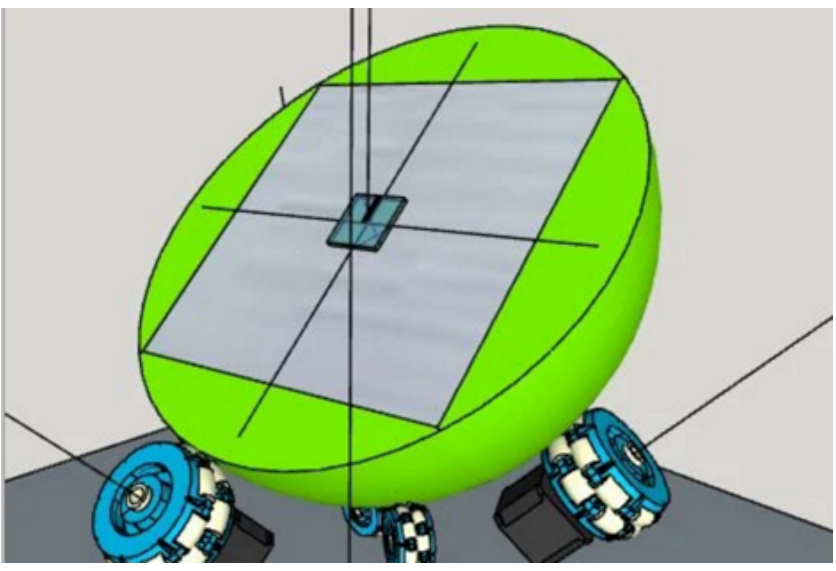

Figure 5. Spherical design concept. CAD by Daniel Brastaviceanu. Image Source: Sensorica

Creating outreach and sustaining community participation were also a challenge, as many of the initial participants dropped out of the project after the ideation phase (see Figure 6 for a graph visualising project engagement). These two factors added to the difficulty of fully documenting the finalised design. Finally, according to the academic partner, the largest challenge, and primary cause of the device delivery delay, was one of accountability. Anyone could participate in the project, but at the same time, anyone could also stop participating. This put pressure on Sensorica's support processes and resulted in some of the affiliates becoming overloaded with tasks, which, in turn, affected on-time delivery of the device.

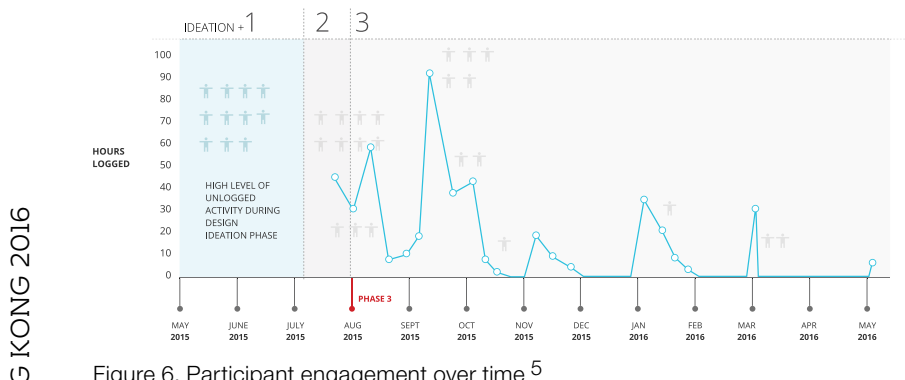

There were issues on the academic side as well. For example, payments to Sensorica took a long time to process. In addition, the distribution of grant funds to the academic partner was contingent on the timely completion of the agreed upon milestones. The project team's inability to meet deadlines diminished the amount of available funds for the research project, putting additional pressure on Sensorica affiliates who rushed to complete and ship the device. Another issue involved different perspectives with regards to Sensorica's role in the design and development of the device. For example, some individuals (at both the academic institution and Sensorica) characterised the academic laboratory's relationship with Sensorica as a classical supplier-client relationship, while others understood the relationship as a lateral collaboration between stakeholders. Finally, from an epistemological perspective, the academic partner and Sensorica held slightly different interpretations of the concept of 'value.' While project participants on both sides agreed that the project did create value, the extent to which it did was subject to debate. For example, Sensorica members felt that the project generated a great deal of social value. While the project lead on the academic side agreed with this assessment, he felt that the project did not generate the kind of economic value he was hoping for.

\section{Discussion}

Analysis revealed that there was tension between the approach used for realising the project's social goals and the reality of designing a 'useful system' (Le Dantec \& Disalvo, 2013). Initial project documents show that the academic partner had specified both (socially) open and (temporally) fixed project requirements for the design of the open source instrument. The first was well-suited to Sensorica's way of working; however, the second posed a number of challenges from a practical perspective; namely, in applying principles of commons-based-peer-production to the design, development of an open source scientific instrument within an academic research setting, and a specified deadline for delivery. As mentioned earlier, these challenges were due, in part, to retaining a steady number of participants throughout the project. However, other challenges were the result of epistemological differences producing differently held priorities and project expectations.

The notion of temporal 'completeness' was also debated. For example, during the online discussion, one affiliate asserted that the scientific instrument should be viewed as a living, "open source artefact," whose future development and improvement would continue beyond Sensorica. A number of participatory design scholars (e.g. Björgvinsson et al., 2010, Björgvinsson et al., 2012; Ehn, 2008; Hillgren, 2011) have characterised the concept of temporality in design activities as a shift from product to process, or from specific project toward future possibilities. This type of approach is at odds with the way scientists typically undertake research projects, and, on a more practical level, with the way in which those projects are funded.

In terms of value creation, proponents of comons-based-peer-production privilege socialised aspects of the design and development process (such as enabling future development and remixing of the open source designs). Design researchers found that these open-ended processes afford innovation outcomes that would otherwise be difficult to achieve with a more structured project approach, revealing new opportunities and directions (e.g. Björgvinsson et al., 2010; Hillgren et al., 2011). However, in this particular

\footnotetext{
3 The NRP-VAS was designed with Bob Haugen and Lynn Foster of Mikorizal Software, who did the development work in collaboration with Sensorica affiliates

4 Open value network - http://valuenetwork.referata.com/wiki/Main_Page
} 
case, the academic partner was concerned with short-term practical goals as determinants of value, such as limiting both production costs and time. Each of these project perspectives is typically served with a different approach to design.

Le Dantec and Disalvo (2013) have characterised the differences between these design approaches as 'design as infrastructuring' (or 'design-for-future-use'), and design of a practical or useful system, or 'design-for-use.' However, although these authors demonstrate that there are inherent differences between infrastructuring as a design approach (one that opens up possibilities toward future applications of a design), and design-for-use (an approach that "narrows possibilities through practical design moves") (Le Dantec \& Disalvo, 2013, 257), they also argue that the two can complement one another. In the context of this study, there is an opportunity to reconcile socialised and open-ended processes taking place within an open value network with product oriented goals, by using an integrated design approach - one that address both future possibilities and current conditions. Recommendations for future development are discussed below.

\section{Lessons Learned / Recommendations for Future Development}

A number of project participants shared their recommendations for improving $\mathrm{OSH}$ production processes within an open value network. These can be classified in the following categories: workflow; participatory design and 'value'; and engagement. The goal is to expand upon these ideas, apply them to a future project, and evaluate them.

\section{1) Workflow}

Stakeholders and participants had different ideas about how to prioritise project objectives (socially open versus temporally fixed production goals). Recommendations:

- Establish clear criteria for project objectives and expectations. What kind of project is it (e.g. a work in progress, a working prototype, a finished product)? What are the short-term deliverables and deadlines? What are the future applications and to what extent should these be addressed?

- Develop and implement project onboarding. Sensorica should work toward helping partner institutions / stakeholders understand OVN principles so that everyone involved has an understanding of the environment in which they will be participating.

- Create a central location for documentation and communication so that existing and new members can access project documents, email threads, decisions, etc.

- Create a dedicated budget for the position of 'project lead(s)' with a clear outline of responsibilities. Tasks could include ensuring that all project milestones and deliverables are met; verifying that all product build steps are well documented and easy to follow; and coordinating meetings and other activities with both the project team and partner institution. As this role is time intensive, a rotating project lead role is recommended.

\section{2) Participatory Design and 'Value'}

A surge of engagement during phase 1 allowed Sensorica to innovate but not to 'complete' the project as expected. In short, product innovation did not result in the kind of value the academic partner was looking for. In order to improve project engagement, and manage expectations, the following recommendations could be implemented:

- Establish project outcomes with respect to a mutually held understanding of what 'value' means (by addressing both future possibilities and current needs) at the onset of each project.

- Implement lean design practices and tools for collaboration to meet short-term production goals. Just as network governance documents and project-specific value equations are the guiding principles of each project, establishing a set of design and production processes (that address product 'value') is critical.

- Create a budget for testing and product support for open source hardware products that are required to work 'out of the box.'

- Define how the project will evolve over time by addressing future work, dissemination of results, and next steps.

\section{3) Engagement}

Over time, there was a loss of momentum and a drop in engagement. Participants in the discussion agreed that incentives alone were not enough and that some form of accountability must be developed to ensure on-time completion of tasks to which members of the project team had committed. Recommendations:

- Revisit governance and implement system of accountability. Sensorica has been talking about creating a reputation system for tracking commitments, however, this is currently a work in progress and requires careful thought and further discussion.

- Develop R\&D processes for OVN with the goal of improving engagement, project commitment and 'ownership.'

- Develop tools that measure engagement (both qualitatively and quantitatively) in order to better understand engagement patterns.

While some of these recommendations are considered standard practice in classical institutions and professional settings, they provide a starting point for developing a more formalised design process to guide self-organised project teams in meeting shortterm production goals within an open value network.

5 There was considerable activity during the ideation phase in May and June, before the project had officially begun. As a result, the value equation for the project had not yet been entered into the accounting system. The visual representation of this activity on in Figure 6 was compiled by analysing electronic correspondence between project participants in May and June 2015 . 


\section{Conclusion}

Overall, the PV characterisation project provides a good example for enabling open source hardware design by an open value network. The varied and highly original designs were made possible by an open call for participation and address the social objectives of the project. While this brought valuable social and intellectual capital, a more streamlined mechanism is needed to better meet the short-term production needs of academically funded $\mathrm{OSH}$ projects. Once these systems are put into place and evaluated, Sensorica's approach to commons-based peer production can be scaled and applied to the development of other open source scientific hardware projects.

\section{References}

Baden, T., Chagas, A.M., Gage, G., Marzullo, T., Prieto-Godino, L.L. and Euler, T., 2015. Open Labware: 3-D printing your own lab equipment. PLoS Biol, 13(3), p.e1002086.

Baek, S.J. \& Manzini, E. 2012. A Socio-Technical Framework for Collaborative Services. DRS '12 on Research: Uncertainty Contradiction Value, 55-75. Bangkok: Department of Industrial Design Faculty of Architecture, Chulalongkorn University.

Baldwin, C. \& von Hippel, E. 2011. Modeling a Paradigm Shift: From Producer Innovation to User and Open Collaborative Innovation. Organizational Science, 22(6), 1399-1417. http://dx.doi.org/10.2139/ssrn.1502864

Bauwens, M. 2009. Class and Capital in Peer Production. Capital \& Class, 33: pp. 121-141.

Benkler, Y. and H. Nissenbaum. 2006. Commons-Based Peer Production and Virtue. Journal of Political Philosophy, 14(4), 394-419. http://dx.doi.org/10.1111/j.14679760.2006.00235.x

Benkler, Y. 2006. The Wealth of Networks: How Social Production Transforms Markets and Freedom. Yale: University Press.

Björgvinsson, E. 2014. The Making of Cultural Commons: Nasty Old Film Distribution and Funding. In Making Futures: Marginal Notes on Innovation, Design and Democracy. P. Ehn, E.M. Nilsson and R. Topgaard (eds.). Cambridge: MIT Press. CC:BY-NC.

Björgvinsson, E., Ehn, P. Hillgren, P. 2010. Participatory Design and Democratising Innovation. Proceedings from PDC ' 10 on Participation: The Challenge, 41-50. ACM Press.

Björgvinsson, E; Ehn, P. and Hillgren, P-A. 2012. Agonistic Participatory Design: working with marginalised social movements. CoDesign: International Journal of CoCreation in Design and the Arts, 8(2-3), 127-144. http://dx.doi.org/10.1080/157108 82.2012.672577

Bollier, D. 2014. Think Like a Commoner: A Short Introduction to the Life of the Commons. Gabriola Island, BC: New Society Publishers.

Brastaviceanu, T. 2016. Interfaces Between Open Organizations and Classical Institutions - the SENSORICA experience. https://docs.google.com/document/d/1ABmC6YJsszIIPoL-YXU3GF-PLHYOtmQdocBExswh7Lw/edit\#heading=h.s5bv81oltkm9

Coleman, R., Ehn, P., Manzini, E., Fumikazu, M. \& Moore, P. 2014. Open Design: Co-creating our Open Societies Through Design. Hong Kong: HKDI DESIS Lab for Social Research.

Creative Commons. 2016. Creative Commons Licenses https://creativecommons, org/licenses/

Corsín Jiménez, A. 2014. The Right to Infrastructure: A Prototype for Open source Urbanism. Environment and Planning D: Society and Space, 32(2). pp.342-362. doi: $10.1068 / \mathrm{d} 13077 \mathrm{p}$

Ehn, P. 2008. Participation in Design Things. Proceedings from PDC '08 on Participatory Design: Experiences and Challenges, 92-101. ACM Press.

Gibb, A. 2014. Building Open source Hardware: DIY Manufacturing for Hackers and Makers. Boston: Addison-Wesley.

Halpern, M.K., Erikson, I., Forlano, L. \& Gay, G. 2013. Designing Collaboration: Comparing Cases Exploring Cultural Probes as Boundary-Negotiating Objects. CSCW '13 on Computer Supported Cooperative Work and Social Computing, 1093-1102. ACM Press.

Hess, C. \& Ostrom, E. 2006. Understanding Knowledge as a Commons From Theory to Practice. Cambridge: MIT Press.

Hess, C. \& Ostrom, E. 2007. Introduction: An Overview of the Knowledge Commons Cambridge: MIT Press.

Hillgren, P. Seravalli, A. Emilson, A. 2011. Prototyping and infrastructuring in design for social innovation. CoDesign, 7(3-4), 169-183.

Karasti, H. \& Syrjänen, A-L. 2004. Artful Infrastructuring in Two Cases of Community PD. Proceedings from PDC '04 on Participatory Design, 20-30. ACM Press.

Langlois, R. \& Garzarelli, G. 2008. Of Hackers and Hairdressers: Modularity and 
the Organizational Economics of Open-source Collaboration. Industry \& Innovation, 15(2), 125-143. http://dx.doi.org/10.1080/13662710801954559

Le Dantec, C. \& DiSalvo, C. 2013. Infrastructuring and the Formation of Publics in Participatory Design. Social Studies of Science, 43(2), 241-264. http://dx.doi. org/10.1177/0306312712471581

Marttila, S. and Botero, A. 2013. The 'Openness Turn' in Co-design. From Usability, Sociability and Designability Towards Openness. Co-Create 2013: The Boundary-Crossing Conference on Co-Design in Innovation. pp.99-110. Finland: Aalto University.

Marttila, S., Botero, A., Saad-Sulonen, J. 2014. Towards Commons Design in Participatory Design. PDC'14. Proceedings from the 13th Participatory Design Conference on Short Papers, Industry Cases, Workshop Descriptions, Doctoral Consortium papers, and Keynote abstracts, Volume 2. Pp.9-12. ACM Press. doi: $10.1145 / 2662155.2662187$

Meyer, T., Khalid, A., Anastassiou, J., Brastaviceanu, T. 2015. Automated Tilt Angle and Orientation Angle System for PV Measurements QE System: Milestone 1 Report - Design Characteristics. https://drive.google.com/file/d/OBzrQyEif2HItd3JXQ3NROXI2WUE/view

Mista, C., Zalazar, M., Peñalva, A., Martina, M. and Reta, J.M., 2016, April. Open source Quartz Crystal Microbalance with dissipation monitoring. In Journal of Physics: Conference Series (Vol. 705, No. 1, p. 012008). IOP Publishing.

OSHWA. 2016a. Open source Hardware (OSHW) Statement of Principles 1.0. http:// www.oshwa.org/definition/

OSHWA. 2016b. Brief History of Open source Hardware Organizations and Definitions http://www.oshwa.org/research/brief-history-of-open source-hardware-organizations-and-definitions

Pearce, J.M., 2012. Building research equipment with free, open source hardware. Science, 337(6100), pp.1303-1304.

Pearce, J.M. Open source Lab: How to Build Your Own Hardware and Reduce Research Costs, Elsevier, 2014

Pearce, J.M., 2015a. Quantifying the value of open source hardware development Modern Economy, 6(1), 1-11. doi: 10.4236/me.2015.61001

Pearce, J.M., 2015. Return on investment for open source scientific hardware development. Science and Public Policy, p.scv034. doi :10.1093/scipol/scv034

Petzel, R., Archer, A.M. \& Fei, R. 2010. Collaboration for Sustainability in a Networked World. Procedia Social and Behavioral Sciences, 2, 6597-6609. http://dx.doi. org/10.1016/j.sbspro.2010.04.070

Phillips, S. \& Baurley, S. 2007. Exploring Open Design for the Application of Citizen Science; a Toolkit Methodology Robert. DRS ‘14 on Design's Big Debates: Pushing the Boundaries of Design Research.

Phillips , R. Baurley, S, \& Silve, S. 2014. Citizen Science and Open Design: Workshop Findings. Design Issues, 30(4), 52-66. http://dx.doi.org/10.1162/DESI

Raasch, C. 2011. Product Development in Open Design Communities: a Process Perspective. International Journal of Innovation and Technology Management, 8(4), 557-575. http://dx.doi.org/10.1142/s021987701100260x

Raasch, C., Herstatt, C. \& Balka, K. 2009. On the Open Design of Tangible Goods R\&D Management, 39(4), 382-393. http://dx.doi.org/10.1007/978-3-8349-6949-1_6

Schausberger, S.E., Kaltseis, R., Drack, M., Cakmak, U.D., Major, Z. and Bauer, S. 2015. Cost-efficient open source desktop size radial stretching system with force sensor. IEEE Access, 3, pp.556-561.

Seravalli, A. 2012. Seravalli, A. (2012). Infrastructuring for opening production, from participatory design to participatory making? PDC' 2012, Proceedings from the 13th Participatory Design Conference. pp.53-56. ACM Press.

Seravalli, A. 2013. Prototyping for opening production: from designing for to designing in the making together. Crafting the Future. Proceedings from the 10th European Academy of Design Conference. 1-17.

Siefkes, C. 2012. The Boom of Commons-Based Peer Production. In D. Bollier \& S. Helfrich (eds.) The Wealth of the Commons: A World Beyond Market and State. Massachusetts: Levellers Press.
TAPR. 2016. The TAPR Open Hardware License. http://www.tapr.org/ohl.html

van Abel, B. Klaassen, R., Evers, L. \& Troxler, P. (eds.). (2011). Open Design Now: Why Design Cannot Remain Exclusive. http://opendesignnow.org/

Zhang, C., Anzalone, N.C., Faria, R.P. and Pearce, J.M. 2013. Open source 3D-printable optics equipment. PLoS one, 8(3), p.e59840.

Ziaie, P. 2014. A Model for Context in the Design of Open Production Communities. ACM Computing Surveys, 47(2), Article 29, 1-29. http://dx.doi.org/10.1145/2661642 